\title{
ANALISIS PENGARUH PENGETAHUAN TENTANG SEKS TERHADAP PERILAKU SEKSUAL REMAJA DI INDONESIA MENGGUNAKAN REGRESI LOGISTIK MULTINOMIAL*
}

\author{
Muhammad Ricky Pranata ${ }^{1}$ and Ray Sastri2 ${ }^{2 \ddagger}$
1Badan Pusat Statistik Kabupaten Paser, Indonesia, rikcy.pranata@bps.go.id 2Politeknik Statistika STIS, Indonesia, raysastri@stis.ac.id Fcorresponding author

Indonesian Journal of Statistics and Its Applications (elSSN:2599-0802) Vol 4 No 1 (2020), 1 - 10

Copyright $@ 2020$ Muhammad Ricky Pranata and Ray Sastri. This is an open-access article distributed under the Creative Commons Attribution License, which permits unrestricted use, distribution, and reproduction in any medium, provided the original work is properly cited.

\begin{abstract}
Sexual impulse will begin to appear in a person when entering adolescent age. The adolescent does different things to fulfill their sexual impulse such as holding hands, hugging, kissing, touching and even having sex. Because this is a new experience to them, they need a lot of information about sexuality such as the reproductive system, sexually transmitted diseases, and others. They can get it in school, the internet, or discuss it with others. The way they deal with their sexual impulse is largely determined by their individual characteristics, knowledge, and discussion partners. This study aims to determine the effect of individual characteristics, knowledge, and information sources on adolescent sexual behavior. This study uses data from the Indonesian Demographic and Health Survey (SDKI) in 2012 with a unit of analysis adolescence age of 15-19 years and is never married. The method of analysis uses multinomial logistic regression with adolescent sexual behavior as response variables divided into three categories; quiet (ignore it), minor sexual activity, and serious (touching the sensitive area and or having sex). The conclusion is the individual's background, sexual knowledge, and sources of information influence sexual behavior both in boy and girl. Serious sexual behavior tends to occur in adolescents who do not attend school, a man who understands about contraception, girls who misunderstand about pregnancy, and those who discuss sexuality with friends.
\end{abstract}

Keywords: contraception, IDHS, juvenile delinquency, logistic regression, sexual behavior.

"Received Nov 2018; Accepted Aug 2019; Published online on Feb 2020 


\section{Pendahuluan}

Masa remaja merupakan masa seseorang mulai mengalami perubahan fisik, hormonal, psikologis, maupun sosial. Dorongan seksual pun akan mulai muncul. Setiap individu melakukan cara yang berbeda-beda dalam memenuhi dorongan seksualnya. Beberapa remaja membiarkan saja dorongan seksual tersebut dan tidak melakukan apa-apa dengan lawan jenis, beberapa yang lainnya melakukan perilaku seksual seperti berpegangan tangan dengan lawan jenis, berpelukan, berciuman, meraba daerah sensitif lawan jenis dan bahkan berhubungan seksual. Menurut Badan Pusat Statistik (BPS), pada tahun 2012, 2,7 persen remaja usia 15-19 tahun pernah melakukan hubungan seks pranikah (BPS, 2013). Meskipun persentasenya tidak banyak, tetapi jika dilihat dari banyaknya orang, ini adalah jumlah yang besar. Hal ini menimbulkan pertanyaan tentang pengetahun mereka mengenai seks. Pawestri et al. (2013) melakukan penelitian terhadap perilaku seksual pranikah remaja di suatu Sekolah Menengah Atas (SMA) dengan metode analisis Rank Spearman. Mereka menyimpulkan bahwa pengetahuan seksual menurunkan kecenderungan perilaku seks. Sementara itu, Nurlina dan Laksmi (2017) dalam penelitiannya menyimpulkan bahwa perilaku seksual remaja dipengaruhi oleh kontrol orang tua dan media massa. Bingenheimer et al. (2015) meneliti pengaruh teman terhadap perilaku seksual remaja dan menemukan bahwa yang meningkatkan inisiatif berhubungan seksual adalah teman yang mendukung seks, perbedaan jenis kelamin, umur, tinggal di kota dengan kasus HIV tinggi, putus sekolah, dan tidak tinggal dengan orang tua.

Masalah perilaku seksual remaja ini sangat penting untuk diteliti karena para remaja inilah yang nantinya akan menjadi penerus pembangunan. Kita perlu mengetahui faktor resiko mereka berperilaku seksual, sehingga dapat mencegah perilaku ini tidak menular ke orang lain sekaligus mencegah penularan penyakit kelamin yang disebabkan oleh seks bebas. Selain itu, mengetahui faktor resiko remaja berperilaku seksual juga dapat membantu pemerintah dalam merencakan program-program positif yang sesuai bagi remaja agar mereka lebih memfokuskan diri pada hal-hal positif. Berdasarkan uraian tersebut di atas, penelitian ini bertujuan untuk menjawab pertanyaan berikut; (1) bagaimana gambaran umum perilaku seksual remaja, pengetahun mereka tentang seks, dan sumber informasi seks di Indonesia (2) apakah latar belakang individu, pengetahuan seks, dan sumber informasi berpengaruh terhadap perilaku seksual remaja.

\section{Metodologi Penelitian}

\subsection{Data}

Data yang digunakan pada penelitian ini adalah data primer hasil Survei Demografi dan Kesehatan Indonesia (SDKI) tahun 2012 yang dilakukan oleh BPS. Unit analisis penelitian adalah remaja berusia 15-19 tahun yang sudah balig (menstruasi pada wanita dan mimpi basah pada pria). Jumlah unit analisis adalah 6.010 remaja pria dan 6.075 remaja wanita di seluruh Indonesia. Beberapa variabel penelitian yang digunakan dalam penelitian disajikan pada Tabel 1. 
Tabel 1: Variabel-variabel yang digunakan dalam penelitian.

\begin{tabular}{|c|c|c|c|c|}
\hline Variabel & Keterangan & Kategori & Kode & $\begin{array}{l}\text { Dummy } \\
\text { Variable }\end{array}$ \\
\hline \multirow[t]{3}{*}{$\mathrm{Y}$} & \multirow[t]{3}{*}{ Perilaku seksual } & tidak melakukan* & 0 & - \\
\hline & & $\begin{array}{l}\text { Ringan (pernah berpegangan } \\
\text { tangan dan berciuman) }\end{array}$ & 1 & - \\
\hline & & $\begin{array}{l}\text { Berat (pernah meraba daerah } \\
\text { sensitif dan melakukan hubungan } \\
\text { seksual) }\end{array}$ & 2 & - \\
\hline \multirow[t]{2}{*}{$X_{1}$} & \multirow[t]{2}{*}{ Tempat tinggal } & Kota & 0 & $D_{1}$ \\
\hline & & desa* $^{*}$ & 1 & - \\
\hline \multirow[t]{2}{*}{$\mathrm{X}_{2}$} & \multirow[t]{2}{*}{ Status bersekolah } & Tidak & 0 & $\mathrm{D}_{2}$ \\
\hline & & $\mathrm{ya}^{*}$ & 1 & - \\
\hline \multirow[t]{3}{*}{$X_{3}$} & \multirow[t]{3}{*}{$\begin{array}{l}\text { Pengetahuan } \\
\text { tentang pubertas }\end{array}$} & $\begin{array}{l}\text { Baik (dapat menyebutkan min } 1 \\
\text { tanda pubertas pada kedua jenis } \\
\text { kelamin) }\end{array}$ & 0 & $D_{31}$ \\
\hline & & $\begin{array}{l}\text { Cukup (dapat menyebutkan min } 1 \\
\text { tanda pubertas pada } 1 \text { jenis } \\
\text { kelamin) }\end{array}$ & 1 & $D_{32}$ \\
\hline & & $\begin{array}{l}\text { kurang* (tidak mengetahui tanda }^{*} \\
\text { pubertas) }\end{array}$ & 2 & - \\
\hline \multirow[t]{3}{*}{$\mathrm{X}_{4}$} & \multirow[t]{3}{*}{$\begin{array}{l}\text { Pengetahuan } \\
\text { tentang masa subur }\end{array}$} & $\begin{array}{l}\text { Benar (hubungan seksual sekali } \\
\text { saja dapat menyebabkan } \\
\text { kehamilan) }\end{array}$ & 0 & $D_{41}$ \\
\hline & & $\begin{array}{l}\text { Salah (kehamilan terjadi setelah } \\
\text { berkali-kali berhubungan seksual) }\end{array}$ & 1 & $\mathrm{D}_{42}$ \\
\hline & & tidak tahu* & 2 & - \\
\hline \multirow[t]{3}{*}{$X_{5}$} & \multirow{3}{*}{$\begin{array}{l}\text { Pengetahuan } \\
\text { tentang kehamilan }\end{array}$} & Benar & 0 & $D_{51}$ \\
\hline & & Salah & 1 & $D_{52}$ \\
\hline & & tidak tahu* & 2 & - \\
\hline \multirow[t]{2}{*}{$X_{6}$} & \multirow{2}{*}{$\begin{array}{l}\text { Pengetahuan } \\
\text { tentang AIDS }\end{array}$} & Tahu (pernah mendengar) & 0 & $D_{6}$ \\
\hline & & tidak tahu* & 1 & - \\
\hline \multirow[t]{2}{*}{$X_{7}$} & \multirow[t]{2}{*}{$\begin{array}{l}\text { Pengetahuan } \\
\text { tentang kontrasepsi }\end{array}$} & $\begin{array}{l}\text { Tahu (mengenal min. } 1 \text { jenis } \\
\text { metode kontrasepsi) }\end{array}$ & 0 & $\mathrm{D}_{7}$ \\
\hline & & tidak tahu* ${ }^{*}$ & 1 & - \\
\hline \multirow[t]{2}{*}{$X_{8}$} & \multirow[t]{2}{*}{$\begin{array}{l}\text { Mendapatkan materi } \\
\text { seksual di sekolah }\end{array}$} & $\begin{array}{l}\text { Ya (salah satu dari: sistem } \\
\text { reproduksi manusia, cara mengatur } \\
\text { kelahiran, HIV/AIDS, dan infeksi } \\
\text { menular lainnya) }\end{array}$ & 0 & $\mathrm{D}_{8}$ \\
\hline & & tidak $^{*}$ & 1 & - \\
\hline \multirow[t]{2}{*}{$\mathrm{X}_{9}$} & \multirow{2}{*}{$\begin{array}{l}\text { Diskusi dengan } \\
\text { teman mengenai } \\
\text { seksualitas }\end{array}$} & $\mathrm{Ya}$ & 0 & $D_{9}$ \\
\hline & & tidak $^{*}$ & 1 & - \\
\hline \multirow[t]{2}{*}{$X_{10}$} & \multirow{2}{*}{$\begin{array}{l}\text { Diskusi dengan ibu } \\
\text { mengenai } \\
\text { seksualitas }\end{array}$} & $\mathrm{Ya}$ & 0 & $D_{10}$ \\
\hline & & tidak $^{*}$ & 1 & - \\
\hline \multirow[t]{2}{*}{$X_{11}$} & \multirow{2}{*}{$\begin{array}{l}\text { Diskusi dengan ayah } \\
\text { mengenai } \\
\text { seksualitas }\end{array}$} & $\mathrm{Ya}$ & 0 & $D_{11}$ \\
\hline & & tidak $^{*}$ & 1 & - \\
\hline
\end{tabular}




\subsection{Metode Analisis}

Metode analisis yang digunakan dalam penelitian ini adalah metode regresi logistik multinomial. Pada metode regresi logistik multinomial, akan dibentuk dua persamaan logit, masing-masing untuk kategori perilaku seksual ringan ( $\mathrm{Y}=1)$ dan perilaku seksual berat $(\mathrm{Y}=2)$, dengan kategori "tidak melakukan" $(\mathrm{Y}=0)$ sebagai kategori referensi.Kedua fungsi logit dapat dinyatakan sebagai berikut:

$$
\begin{aligned}
& g_{1}(x)=\ln \left[\frac{P(Y=1 \vee x)}{P(Y=0 \vee x)}\right]=\beta_{10}+\beta_{11} x_{1}+\cdots+\beta_{1 p} x_{p} \\
& g_{2}(x)=\ln \left[\frac{P(Y=2 \vee x)}{P(Y=0 \vee x)}\right]=\beta_{20}+\beta_{21} x_{1}+\cdots+\beta_{2 p} x_{p}
\end{aligned}
$$

Persamaan umum dari regresi logistik multinomial untuk tiga kategori variabel dependen adalah:

$$
P(Y=j)=\frac{\exp \left[g_{j}(x)\right]}{\sum_{k=0}^{2} \exp \left[g_{k}(x)\right]} ; j=0,1,2 ; g_{0}(x)=0
$$

dengan $g_{j}(x)$ : Fungsi logit pada model regresi logistik kategori j.

Pada regresi logistik multinomial, parameter diduga dengan menggunakan Maximum Likelihood Estimation (MLE), dengan memaksimumkan fungsi kemungkinan dari sampel acak untuk menduga parameter. Solusi untuk $\beta$ didapatkan dengan metode iterasi Newton Raphson (Hosmer dan Lemeshow, 2000). Dalam penelitian ini menggunakan software SPSS.

Uji Goodness of Fit menggunakan metode Pearson Chi-Square (Agresti, 2003) dengan hipotesis nol model fit dan hipotesis alternatif model tidak fit. Statistik uji-nya adalah sebagai berikut:

$$
X^{2}=\sum_{j} \frac{\left(n_{j}-\mu_{j}\right)^{2}}{\mu_{j}} \sim \chi_{(k-1)}^{2}
$$

Dimana $n_{j}$ adalah frekuensi observasi pada kategori respon ke-j dan $\mu_{j}$ adalah frekuensi harapan pada kategori respon ke-j. $\mathrm{H}_{0}$ ditolak jika $X^{2} \geq \chi_{(\alpha ; k-1)}^{2}$ atau $p$-value $\leq \alpha$.

Ukuran kekuatan model yang dihasilkan dalam regresi logistik dapat dilihat dari nilai pseudo- $R^{2}$-nya. Nilai pseudo- $R^{2}$ menunjukkan besarnya kontribusi variabelvariabel penjelas dalam penelitian terhadap variabel respon. Setelah dilakukan pendugaan parameter dan pengujian model, kemudian dilakukan pengujian parameter secara simultan dan secara parsial. Pengujian simultan parameter dilakukan dengan hipotesis nol tidak ada pengaruh dari variabel penjelas terhadap variabel respons dan hipotesis alternatif minimal ada satu variabel penjelas yang berpengaruh terhadap variabel respons. Statistik uji yang digunakan adalah:

$$
G=-2 \ln \left(\frac{\text { Likelihoodnullmodel }}{\text { Likelihoodconditionalmodel }}\right) \sim \chi_{(p)}^{2}
$$


Dimana tolak $\mathrm{H}_{0}$ jika $G \geq \chi_{(\alpha ; p)}^{2}$ atau $p$-value $\leq \alpha$. Sementara itu, pengujian parameter secara parsial menggunakan uji Wald dengan hipotesis nol Tidak ada pengaruh dari variabel penjelas ke-k terhadap variabel respons pada model logit ke-j dan hipotesis alternatif terdapat pengaruh dari variabel penjelas ke-k terhadap variabel respons pada model logit ke-j. Statistik uji yang digunakan adalah sebagai berikut:

$$
W_{j k}=\left(\frac{\hat{\beta}_{j k}}{s e\left(\hat{\beta}_{j k}\right)}\right)^{2} \sim \chi_{(1 ; \alpha)}^{2}
$$

Kita akan menolak hipotesis nol jika $W_{j k} \geq \chi_{(1 ; \alpha)}^{2}$ atau $p$-value $\leq \alpha$

\subsection{Rasio Kecenderungan (Odds Ratio)}

Pada model dengan tiga kategori variabel respons, odds ratio dihitung untuk perbandingan antara variabel respons kategori 1 terhadap kategori 0 dan kategori 2 terhadap 0 . Sebagai contoh, odds ratio untuk variabel $\mathrm{X}_{1}$ dihitung sebagai berikut:

$$
\begin{aligned}
& O R_{1}=\frac{\exp \left(\beta_{10}+\beta_{11}(1)+\beta_{12}(0)+\cdots+\beta_{1 p}(0)\right)}{\exp \left(\beta_{10}+\beta_{11}(0)+\beta_{12}(0)+\cdots+\beta_{1 p}(0)\right)}=e^{\beta_{11}} \\
& O R_{2}=\frac{\exp \left(\beta_{20}+\beta_{21}(1)+\beta_{22}(0)+\cdots+\beta_{2 p}(0)\right)}{\exp \left(\beta_{20}+\beta_{21}(0)+\beta_{22}(0)+\cdots+\beta_{2 p}(0)\right)}=e^{\beta_{21}}
\end{aligned}
$$

\section{Hasil dan Pembahasan}

\subsection{Gambaran Umum Perilaku Remaja}

Persentase remaja pria usia 15-19 tahun yang pernah melakukan perilaku seksual berat adalah sebesar 25 persen, jauh lebih banyak dibandikan pada remaja wanita yang hanya sebesar 5 persen. Sementara itu, 61 persen remaja wanita pernah melakukan perilaku seksual ringan, lebih tinggi dibandingkan persentase pada remaja pria yaitu 49 persen. Persentase remaja pria yang tidak melakukan tindakan yang tergolong perilaku seksual hampir sama dengan yang melakukan perilaku seksual berat yaitu 26 persen, sementara pada remaja wanita 34 persen. Lebih jelasnya dapat dilihat pada Gambar 1.

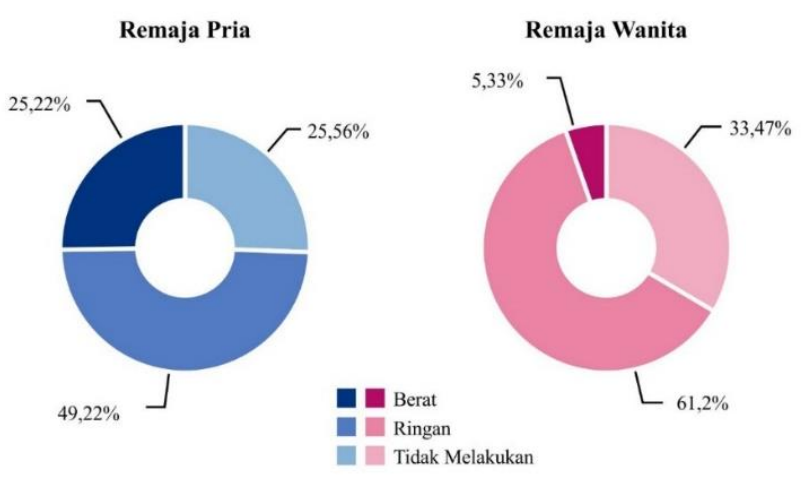

Gambar 1: Persentase kategori perilaku seksual remaja pria dan remaja wanita. 
Dalam pengetahuan seksual, di beberapa subjek seperti tanda-tanda pubertas dan AIDS, pengetahuan remaja wanita lebih baik dibanding remaja pria, sedangkan pada subjek lainnya seperti masa subur, kehamilan, dan kontrasepsi, pengetahuan remaja pria relatif seimbang dengan remaja wanita. Sebanyak 88,3 persen remaja wanita dapat menyebutkan tanda pubertas laki-laki dan perempuan, sedangkan pada remaja pria hanya 76,3 persen yang dapat menyebutkan keduanya. Remaja pria yang tidak dapat menyebutkan tanda pubertas pada laki-laki maupun perempuan adalah sebanyak 8,8 persen, pada remaja wanita hanya 5,2 persen. Secara lengkap dapat disajikan pada Gambar 2.
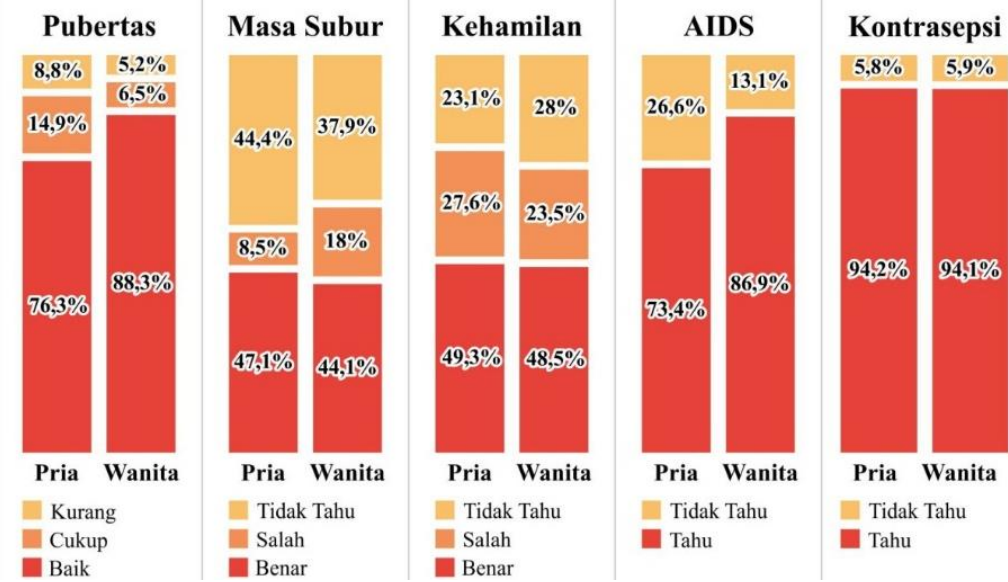

Gambar 2: Persentase remaja pria dan wanita menurut pengetahuan seksual.

Sebanyak 44,4 persen remaja pria dan 37,9 persen remaja wanita mengaku tidak tahu tentang masa subur. Namun, sebanyak 18 persen remaja wanita yang mengaku tahu tentang masa subur ternyata salah dalam memahami masa subur. Persentase remaja pria yang memahami masa subur dengan benar justru lebih besar dibanding remaja wanita, yaitu 47,1 persen dan 44,1 persen. Mengenai kehamilan, 23,1 persen remaja pria dan 28 persen remaja wanita tidak tahu apakah seorang wanita dapat hamil hanya dengan sekali melakukan hubungan seksual. 49,3 persen remaja pria dan 48 persen remaja wanita menjawab dengan benar dan sisanya yaitu 27,6 persen remaja pria dan 23,5 persen remaja wanita menjawab dengan salah. Sebanyak 13,1 persen remaja wanita tidak pernah mendengar tentang AIDS. Pada remaja pria, 26,6 persen atau lebih dari dua kali persentase remaja wanita tidak pernah mendengar tentang AIDS. Persentase remaja pria dan remaja wanita yang tahu metode kontrasepsi relatif seimbang yaitu 94,24 persen dan 94,12 persen.

Dari sumber informasinya mengenai seksualitas, hampir semua remaja sudah mendapatkan informasi mengenai seksualitas di sekolah. Untuk teman berdiskusi, diskusi masalah seksual yang paling banyak dilakukan oleh remaja pria maupun wanita adalah dengan teman, yaitu sebanyak 72,2 persen remaja pria dan 75,3 persen remaja wanita. Perbedaan persentase terbesar adalah pada variabel diskusi dengan ibu. Remaja wanita yang berdiskusi masalah seksual dengan ibu adalah sebanyak 56,7 persen, sedangan remaja pria hanya 10,8 persen atau kurang dari seperlima persentase remaja wanita Walaupun dengan angka yang relatif kecil, persentase 
remaja pria yang berdiskusi masalah seksual dengan ayahnya dua kali lebih banyak daripada remaja wanita, yaitu 9,53 persen dan 4,51 persen. Gambar 3 memvisualisasikan perbandingan persentase ini.
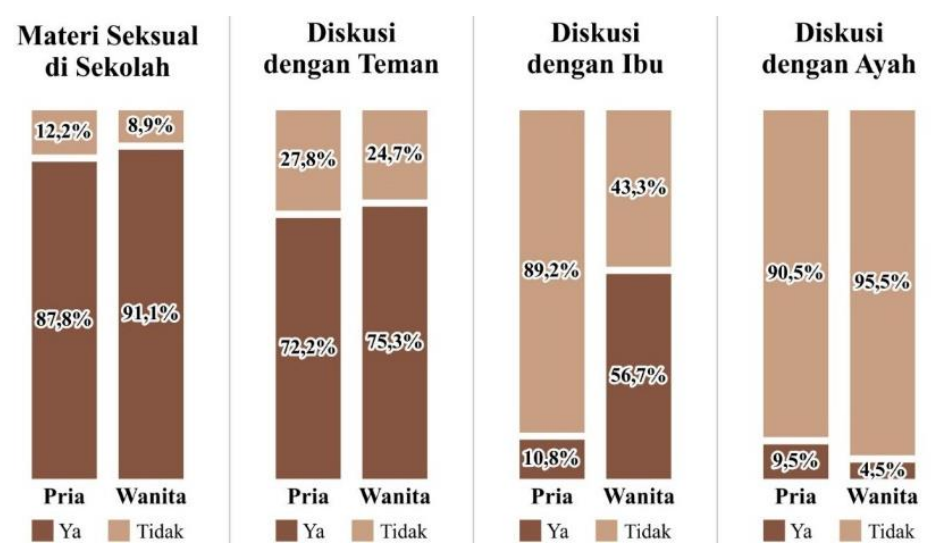

Gambar 3: Persentase remaja pria dan wanita menurut sumber informasi.

\subsection{Pengaruh Latar Belakang Individu, Pengetahuan Seks, dan Sumber Informasi Berpengaruh Terhadap Perilaku Seksual Remaja}

Dengan menggunakan regresi logistik multinomial, dibentuk dua model, model untuk perilaku seksual ringan dan model untuk perilaku seksual berat pada remaja pria dan remaja wanita. Masing-masing estimasi parameter dan signifikansi dari persamaan logit yang terbentuk disajikan pada Tabel 2 dan Tabel 3.

Tabel 2: Estimasi parameter model remaja pria.

\begin{tabular}{|c|c|c|c|c|c|c|c|c|}
\hline \multirow{2}{*}{\multicolumn{2}{|c|}{ Variabel }} & \multirow{2}{*}{$\begin{array}{c}\text { Dum } \\
\text { my } \\
\text { Var. }\end{array}$} & \multicolumn{3}{|c|}{ Ringan } & \multicolumn{3}{|c|}{ Berat } \\
\hline & & & $B$ & $p$-val & $\operatorname{Exp}(B)$ & $B$ & $p$-val & $\operatorname{Exp}(B)$ \\
\hline \multicolumn{2}{|c|}{ Intercept } & - & -1.754 & $0.000^{*}$ & 0.173 & -4.346 & $0.000^{*}$ & 0.013 \\
\hline$X_{1}$ & $\begin{array}{l}\text { Tempat } \\
\text { Tinggal }\end{array}$ & $\mathrm{D}_{1}$ & 0.200 & $0.003^{*}$ & 1.221 & 0.291 & $0.000^{*}$ & 1.338 \\
\hline$X_{2}$ & $\begin{array}{l}\text { Status } \\
\text { Bersekolah }\end{array}$ & $\mathrm{D}_{2}$ & 0.877 & $0.000^{*}$ & 2.404 & 1.441 & $0.000^{*}$ & 4.225 \\
\hline \multirow[t]{2}{*}{$\mathbf{X}_{3}$} & Pubertas & $D_{31}$ & 0.262 & $0.030^{*}$ & 1.300 & 0.331 & $0.029^{*}$ & 1.392 \\
\hline & & $D_{32}$ & 0.190 & 0.161 & 1.209 & 0.118 & 0.498 & 1.125 \\
\hline \multirow[t]{2}{*}{$\mathbf{X}_{4}$} & Masa & $\mathrm{D}_{41}$ & 0.218 & $0.003^{*}$ & 1.244 & 0.559 & $0.000^{*}$ & 1.749 \\
\hline & Subur & $\mathrm{D}_{42}$ & 0.254 & $0.039^{*}$ & 1.289 & 0.337 & $0.023^{*}$ & 1.401 \\
\hline \multirow[t]{2}{*}{$X_{5}$} & Kehamilan & $\mathrm{D}_{51}$ & 0.280 & $0.001^{*}$ & 1.323 & 0.684 & $0.000^{*}$ & 1.982 \\
\hline & & $D_{52}$ & 0.354 & $0.000 *$ & 1.425 & 1.205 & $0.000^{*}$ & 3.337 \\
\hline$X_{6}$ & AIDS & $\mathrm{D}_{6}$ & 0.296 & $0.002^{*}$ & 1.344 & 0.155 & 0.172 & 1.168 \\
\hline$X_{7}$ & Kontrasepsi & $\mathrm{D}_{7}$ & 0.887 & $0.000^{*}$ & 2.428 & 1.631 & $0.000^{*}$ & 5.109 \\
\hline$X_{8}$ & Sekolah & $\mathrm{D}_{8}$ & 0.164 & 0.202 & 1.178 & 0.155 & 0.315 & 1.168 \\
\hline$X_{9}$ & Teman & Dg & 0.503 & $0.000^{*}$ & 1.654 & 0.898 & $0.000^{*}$ & 2.455 \\
\hline$X_{10}$ & lbu & $\mathrm{D}_{10}$ & 0.080 & 0.596 & 1.083 & 0.299 & 0.080 & 1.349 \\
\hline$X_{11}$ & Ayah & $\mathrm{D}_{11}$ & -0.352 & $0,023^{*}$ & 0.703 & -0.560 & $0.002^{*}$ & 0.571 \\
\hline
\end{tabular}


Tabel 3: Estimasi parameter model remaja wanita.

\begin{tabular}{|c|c|c|c|c|c|c|c|c|}
\hline \multirow{2}{*}{\multicolumn{2}{|c|}{ Variabel }} & \multirow{2}{*}{$\begin{array}{c}\text { Dummy } \\
\text { Var. }\end{array}$} & \multicolumn{3}{|c|}{ Ringan } & \multicolumn{3}{|c|}{ Berat } \\
\hline & & & $B$ & $p$-val & $\operatorname{Exp}(B)$ & $B$ & $p$-val & $\operatorname{Exp}(B)$ \\
\hline \multicolumn{2}{|c|}{ Intercept } & - & -1.997 & $0.000^{*}$ & 0.136 & -4.947 & $0.000^{*}$ & 0.007 \\
\hline$X_{1}$ & $\begin{array}{l}\text { Tempat } \\
\text { Tinggal }\end{array}$ & $\mathrm{D}_{1}$ & 0.192 & $0.001^{*}$ & 1.212 & 0.064 & 0.611 & 1.066 \\
\hline$X_{2}$ & $\begin{array}{l}\text { Status } \\
\text { Bersekolah }\end{array}$ & $\mathrm{D}_{2}$ & 0.811 & $0.000^{*}$ & 2.250 & 1.297 & $0.000^{*}$ & 3.658 \\
\hline \multirow[t]{2}{*}{$X_{3}$} & Pubertas & $D_{31}$ & 0.315 & $0.028^{*}$ & 1.370 & 0.486 & 0.146 & 1.626 \\
\hline & & $D_{32}$ & 0.140 & 0.403 & 1.150 & 0.387 & 0.311 & 1.473 \\
\hline \multirow[t]{2}{*}{$\mathbf{X}_{4}$} & Masa & $D_{41}$ & 0.109 & 0.107 & 1.115 & 0.175 & 0.227 & 1.191 \\
\hline & Subur & $D_{42}$ & -0.096 & 0.237 & 0.908 & 0.107 & 0.536 & 1.113 \\
\hline \multirow[t]{2}{*}{$X_{5}$} & Kehamilan & $D_{51}$ & 0.090 & 0.208 & 1.094 & 0.824 & $0.000^{*}$ & 2.280 \\
\hline & & $D_{52}$ & 0.459 & $0.000^{*}$ & 1.582 & 1.510 & $0.000^{*}$ & 4.527 \\
\hline$X_{6}$ & AIDS & $D_{6}$ & 0.475 & $0.000^{*}$ & 1.608 & 0.107 & 0.604 & 1.113 \\
\hline$X_{7}$ & Kontrasepsi & $\mathrm{D}_{7}$ & 0.623 & $0.000^{*}$ & 1.865 & 0.842 & $0.015^{\star}$ & 2.321 \\
\hline$X_{8}$ & Sekolah & $D_{8}$ & 0.489 & $0.000^{*}$ & 1.631 & 0.033 & 0.886 & 1.034 \\
\hline$X_{9}$ & Teman & Dg & 0.415 & $0.000^{*}$ & 1.514 & 0.553 & $0.000^{*}$ & 1.738 \\
\hline$X_{10}$ & lbu & $D_{10}$ & 0.129 & $0.034^{*}$ & 1.138 & -0.106 & 0.412 & 0.899 \\
\hline$X_{11}$ & Ayah & $D_{11}$ & -0.011 & 0.938 & 0.989 & 0.322 & 0.239 & 1.380 \\
\hline
\end{tabular}

Dari hasil pemodelan didapatkan 9 variabel independen yang signifikan berpengaruh pada perilaku seksual ringan pada remaja pria. Variabel tersebut adalah tempat tinggal, status bersekolah, pengetahuan tentang pubertas, pengetahuan tentang masa subur, pengetahuan tentang kehamilan, pengetahuan tentang AIDS, pengetahuan tentang kontrasepsi, diskusi dengan teman, dan diskusi dengan ayah. Materi seksualitas di sekolah dan berdiskusi dengan ibu ternyata tidak signifikan mempengaruhi perilaku seksual remaja. Dari gambar Sedangkan pada perilaku seksual berat, terdapat 8 variabel yang signifikan. variable tersebut sama dengan perilaku seksual ringan, hanya saja pada perilaku seksual berat, pengetahuan tentang AIDS tidak signifikan.

Jika diperhatikan, koefisien regresi pada semua variabel pengetahuan bernilai positif atau odds rasio di lebih dari satu. Ini berarti, memiliki pengetahuan mengenai pubertas, masa subur, kehamilan, AIDS, dan kontrasepsi tidak serta merta membuat seorang remaja menjauhi perilaku seksual baik ringan atau berat. Dari nilai odds rasio dapat dikatakan bahwa kecenderungan seseorang yang memiliki pengetahuan tentang seksualitas dan akibatnya untuk melakukan perbuatan seksual ternyata lebih besar dibandingkan yang tidak tahu.

Beberapa variabel memiliki odds rasio yang sangat berbeda pada model perilaku seksual ringan dan berat. Pada Tabel 2 dapat dilihat bahwa kecenderungan seorang remaja yang tidak bersekolah untuk melakukan perilaku seksual ringan sebesar 2,4 kali dibanding yang tidak bersekolah. Tingkat kecenderungannya lebih besar pada 
perilaku seksual berat, yaitu 4,2 kali. Hal yang sama juga terjadi pada variable kehamilan. Seorang remaja pria yang memiliki pengetahuan yang salah mengenai kehamilan cenderung untuk melakukan perilaku seksual berat 3,3 kali dibanding yang tidak tahu. Sedangkan mengenai kontrasepsi, mereka yang memiliki pengetahuan tentang alat kontrasepsi cenderung untuk melakukan perilaku seksual ringan sebesar 2,4 kali dan perilaku seksual berat 5,1 kali dibanding yang tidak tahu. Hal ini sangat mengejutkan. Pengetahuan tentang alat kontrasepsi telah secara tidak langsung mendukung terjadinya sex bebas.

Diskusi dengan ayah adalah satu-satunya variable yang memiliki koefisien negatif. Seseorang yang berdiskusi dengan ayahnya mengenai seksualtas akan cenderung untuk melakukan hubungan seksual ringan 0,7 kali dibandingkan yang tidak berdiskusi dengan ayah, dan kecenderungan untuk melakukan hubungan seksual berat sebesar 0.57 kali. Dengan kata lain, seorang remaja pria yang tidak berdisusi dengan ayahnya akan cenderung untuk melakukan hubungan seksual ringan 1,4 kali atau hubungan seksual berat 1,8 kali dibanding mereka yang berdiskusi dengan ayahnya. Ini menunjukkan bahwa hubungan yang baik antara seorang remaja pria dengan ayahnya dapat memperkecil kemungkinan seseorang untuk melakukan hubungan seksual di luar pernikahan.

Pada remaja wanita, terdapat 9 variabel yang signifikan mempengaruhi perilaku seksual ringan dan hanya 4 yang mempengaruhi perilaku seksual berat. Hal ini disajikan dalam Tabel 3. Pengetahuan mengenai masa subur dan berdiskusi dengan ayah tidak signifikan pada perilaku seksual ringan. Meskipun signifikan pada remaja pria, pengetahuan tentang masa subur dan berdiskusi dengan ayah ternyata tidak signifikan berpengaruh pada perilaku seksual remaja wanita. Tempat tinggal, pengetahuan tentang pubertas, pengetahuan tentang masa subur, pengetahuan tentang AIDS, materi seksualitas di sekolah, berdiskusi dengan ibu dan ayah tidak signifikan pada perilaku seksual berat remaja wanita. Sama seperti pada remaja pria, pengetahuan mengenai kehamilan yang salah mebuat kecenderungan seseorang untuk melakukan hubungan seksual berat 4,5 kali dibanding yang tidak tahu. Tetapi pengetahuan tentang kehamilan yang benar juga memiliki tingkata kecenderungan yang lebih besar yaitu 2,3 kali dibanding yang tidak tahu.

Mengenai teman berdiskusi, remaja wanita kebalikan dari remaja pria. Pada remaja wanita diskusi dengan ibu signifikan mempengaruhi perilaku seksual sedangkan diskusi dengan ayah tidak. Hal ini wajar, karena pada umumnya remaja wanita memang lebih dekat dengan ibunya. Akan tetapi diskusi dengan ibu tidak signifikan pada perilaku seksual berat. Meskipun tidak signifikan, seorang remaja wanita yang berdiskusi dengan ibu akan cenderung untuk melakukan hubungan seksual berat sebesar 0,9 kali dibanding yang tidak berdiskusi dengan ibu. Dengan kata lain, berdiskusi dengan ibu memberikan dampak positif pada remaja dalam hal mencegah terjadinya seks bebas. 


\section{Simpulan}

Simpulan yang didapatkan dalam penelitian ini adalah latar belakang individu, pengetahuan seks, dan sumber informasi berpengaruh terhadap perilaku seksual remaja baik pria maupun wanita. Perilaku seksual berat cenderung terjadi pada remaja yang tidak bersekolah, remaja pria yang paham kontrasepsi, dan remaja wanita yang salah mengerti tentang kehamilan, serta remaja yang berdiskusi tentang seksualitas dengan teman. Sangat sedikit remaja yang berdiskusi dengan kedua orang tua mereka.

\section{Daftar Pustaka}

Agresti, A. (2003). Categorical data analysis (2nd ed., Vol. 482). New Jersey (US): John Wiley \& Sons.

Bingenheimer, J. B., Asante, E., \& Ahiadeke, C. (2015). Peer influences on sexual activity among adolescents in Ghana. Studies in Family Planning, 46(1): 1-19.

[BPS] Badan Pusat Statistik. (2013). Survei demografi dan kesehatan Indonesia 2012: Kesehatan reproduksi remaja. Jakarta (ID): BPS.

Hosmer, D. W., \& Lemeshow, S. (2000). Applied logistic regression. New York (US): John Wiley \& Sons.

Nurlina, N., \& Laksmi, L. U. (2017). Kontrol orang tua, pengaruh teman sebaya dan media massa berkaitan dengan perilaku seksual remaja. Care: Jurnal IImiah IImu Kesehatan, 5(1): 10-19.

Pawestri, Wardani, R. S., \& Sonna. (2013). Pengetahuan, sikap dan perilaku remaja tentang seks pra nikah. Jurnal Keperawatan Maternitas, 1(1): 46-54. 